\title{
Study of Molecular Interactions in Binary Liquid Mixtures by Acoustical Method at 303K
}

\author{
P. PAUL DIVAKAR ${ }^{\text {A } * \text { B.V.RAO }}{ }^{\mathrm{B}}$, and K. SAMATHA ${ }^{\mathrm{A}}$ \\ ${ }^{a}$ Ultrasonic Laboratories, Department of Physics, \\ Andhra University, Visakhapatnam - 530 003, India \\ ${ }^{\mathrm{b}}$ Department of Engineering Chemistry \\ Andhra University, Visakhapatnam - 530 003, India \\ putla_paul@yahoo.co.in
}

Received 17 July 2011; Accepted 5 September 2011

\begin{abstract}
Ultrasonic velocity and density measurements were made in two binary liquid mixtures Isopropyl acetate (IPA) and Isobutyl acetate (IBA) with cyclohexanone $(\mathrm{CY})$ as a common component at $303 \mathrm{~K}$, at fixed frequency of $2 \mathrm{MHz}$ using single crystal variable path interferometer and specific gravity bottle respectively. The experimental data have been used to calculate the acoustic impedance, adiabatic compressibility, inter molecular free length and molar volume. The excess thermodynamic parameters have been evaluated and discussed in the light of molecular interactions.
\end{abstract}

Keywords: acoustic impedance, adiabatic compressibility, intermolecular free length, molar volume, molecular interactions.

\section{Introduction}

Ultrasonic investigations find extensive applications in characterising thermodynamic and physico-chemical behaviour of binary and ternary liquid mixtures. The measurement of ultrasonic velocities and parameters derived from it have been used in understanding the nature of inter molecular and intra-molecular interactions in binary liquid mixtures[1-6]. The study of intermolecular interactions play an important role in the development of molecular sciences.

Having wide usage in flavouring, perfumery, artificial essences, and cosmetics, esters become one of the industrially important class of liquids. Esters are also used as solvents in pharmaceutical and paint industries and as plasticizers in plastic industries. The commercial use of cyclohexanone includes synthesis of nylon. Hence a fundamental understanding of the mixing behavior of alkyl acetates (isopropyl and isobutyl) with cyclohexanone is important from a technical and engineering view point. 
The present investigation deals with the study of molecular interaction in 2 binary liquid mixtures at $303 \mathrm{~K}$.

System-I: cyclohexanone + Isopropyl acetate ( CY+IPA )

System-II: cyclohexanone + Isobutyl acetate ( CY+IBA )

\section{Experimental}

The velocity of ultrasonic waves in the liquid mixture have been measured using a single crystal variable path ultrasonic interferometer ( Model-F81, Mittal Enterprises, New Delhi) measured at $303 \mathrm{~K}$ using $10 \mathrm{ml}$ specific gravity bottle by the standard procedure with an accuracy of $\pm 0.1 \mathrm{~kg} \mathrm{~m}-3$. The constant temperature was maintained by using thermostat throughout the experiment.

\section{Theoretical Aspects}

Various Physical and thermodynamical parameters are calculated using the measured parameters, viz., the ultrasonic velocity $(\mathrm{U})$ and density $(\rho)$.

$$
\begin{array}{lll}
\text { 1. Acoustical Impedance } & \mathrm{Z}=\rho \mathrm{U} & \mathrm{kg}-\mathrm{m}^{2} / \mathrm{sec} \\
\text { 2. Adiabatic Compressibility } & \beta=1 /(\rho \mathrm{U} 2) & \mathrm{m}^{2} / \mathrm{N} \\
\text { 3. Intermolecular free length } & \mathrm{L}_{\mathrm{f}}=\mathrm{k}(\beta) 1 / 2 & \mathrm{~m}
\end{array}
$$

where $\mathrm{k}$ is a temperature dependent constant. It's value is $201.1209 \times 10-8$ at $303 \mathrm{~K}$.

$$
\text { 4. Molar volume } \quad \mathrm{V}_{\mathrm{m}}=\mathrm{M}_{\text {mix }} / \rho \quad \mathrm{m3} / \text { mole }
$$

where Mmix is the molecular weight of the mixture in which $\mathrm{M}_{\text {mix }}=\Sigma \mathrm{mi} \mathrm{xi}$

Here mi and xi are the molecular weight and the mole fraction of the individual constituents respectively.

The excess values are calculated using the general formula, $A^{E}=A_{\exp }-A_{i d}$ where, $A_{i d}=\sum A_{i} x_{i}$ where $A_{i}$ is any acoustical parameter and $x_{i}$ is the mole fraction of liquid component.

\section{Results and Discussion}

Table 1 shows the values of ultrasonic velocity $(U)$,density $(\rho)$ and excess acoustical impedance $\left(Z^{\mathrm{E}}\right)$, excess adiabatic compressibility $\left(\beta^{\mathrm{E}}\right)$, excess free length $\left(\mathrm{L}_{\mathrm{f}}^{\mathrm{E}}\right)$ and excess molar volume $\left(\mathrm{V}_{\mathrm{m}}^{\mathrm{E}}\right)$ for cyclohexanone + Isopropyl acetate / Isobutyl acetate at $303 \mathrm{~K}$.

From the Table-1, it is observed that ultrasonic velocity (U) and density $(\rho)$ increases with increasing in the mole fraction of cyclohexanone in both the binary systems. This behavior can be attributed to intermolecular interactions in the systems studied [7-8] and may be due to the depolymerization of alkyl acetates caused by the addition of cyclohexanone. 
Table 1. Experimental values of ultrasonic velocity $(U)$, density $(\rho)$ and excess acoustical impedance $\left(Z^{\mathrm{E}}\right)$, excess adiabatic compressibility $\left(\beta^{\mathrm{E}}\right)$, excess free length $\left(\mathrm{L}_{\mathrm{f}}{ }^{\mathrm{E}}\right)$ and excess molar volume $\left(\mathrm{V}_{\mathrm{m}}^{\mathrm{E}}\right)$ for cyclohexanone + Isopropyl acetate / Isobutyl acetate at $303 \mathrm{~K}$.

\begin{tabular}{|c|c|c|c|c|c|c|c|}
\hline $\begin{array}{c}\mathrm{X}_{1} \\
\text { Mole } \\
\text { Fraction } \\
\text { of CY }\end{array}$ & $\begin{array}{c}\mathrm{X}_{2} \\
\text { Mole } \\
\text { Fraction } \\
\text { of IPA/ } \\
\text { IBA }\end{array}$ & $\begin{array}{c}\mathrm{U} \\
\mathrm{m} / \mathrm{sec}\end{array}$ & $\begin{array}{c}\rho \\
\mathrm{Kg} / \mathrm{m} 3\end{array}$ & $\begin{array}{c}\mathrm{Z}^{\mathrm{E}} \\
\mathrm{X} 10^{-3} \\
\mathrm{Kg}-\mathrm{m}^{2} \\
/ \mathrm{sec}\end{array}$ & $\begin{array}{c}\beta^{\mathrm{E}} \\
X 10^{-11} \\
\mathrm{~m}^{2} / \mathrm{N}\end{array}$ & $\begin{array}{c}\mathrm{L}_{\mathrm{f}}^{\mathrm{E}} \\
\times 10^{-12} \\
\mathrm{~m}\end{array}$ & $\begin{array}{c}\mathrm{V}_{\mathrm{m}}^{\mathrm{E}} \\
{\mathrm{X} 10^{-7}}^{\mathrm{m}^{3} /} \\
\mathrm{mole}\end{array}$ \\
\hline
\end{tabular}

Cyclohexanone + Isopropyl acetate

\begin{tabular}{|c|c|c|c|c|c|c|c|}
\hline 0.0000 & 1.0000 & 1096.9 & 861.6 & 0.000 & 0.0000 & 0.0000 & 0.0000 \\
\hline 0.1123 & 0.8877 & 1108.9 & 865.9 & -2.811 & 2.2907 & 0.9966 & 5.3801 \\
\hline 0.2218 & 0.7782 & 1123.9 & 871.1 & -5.143 & 3.9700 & 1.7666 & 9.3857 \\
\hline 0.3284 & 0.6716 & 1141.1 & 876.7 & -7.109 & 5.2782 & 2.3851 & 12.716 \\
\hline 0.4321 & 0.5679 & 1159.1 & 882.5 & -8.850 & 6.4862 & 2.9430 & 15.651 \\
\hline 0.5329 & 0.4671 & 1192.2 & 891.8 & -8.700 & 5.3772 & 2.6265 & 14.033 \\
\hline 0.6312 & 0.3688 & 1230.8 & 902.1 & -7.773 & 3.8942 & 2.0970 & 11.272 \\
\hline 0.7270 & 0.2730 & 1270.8 & 912.4 & -6.543 & 2.7106 & 1.6028 & 8.6419 \\
\hline 0.8202 & 0.1798 & 1313.2 & 922.8 & -4.896 & 1.6959 & 1.0992 & 5.9985 \\
\hline 0.9113 & 0.0887 & 1359.1 & 933.5 & -2.713 & 0.7736 & 0.5565 & 3.1611 \\
\hline 1.0000 & 0.0000 & 1408.0 & 944.6 & 0.000 & 0.0000 & 0.0000 & 0.0000 \\
\hline \multicolumn{8}{|c|}{ Cyclohexanone + Isobutyl acetate } \\
\hline 0.0000 & 1.0000 & 1134.8 & 860.1 & 0.0000 & 0.0000 & 0.0000 & 0.0000 \\
\hline 0.1259 & 0.8741 & 1152.6 & 866.5 & -2.1876 & 1.2302 & 0.6227 & 3.0717 \\
\hline 0.2452 & 0.7548 & 1169.2 & 872.8 & -4.2353 & 2.5718 & 1.2541 & 6.1261 \\
\hline 0.3579 & 0.6421 & 1185.6 & 879.1 & -6.0656 & 3.8237 & 1.8206 & 8.9598 \\
\hline 0.4642 & 0.5358 & 1201.7 & 884.8 & -7.7083 & 5.1011 & 2.3849 & 12.398 \\
\hline 0.5652 & 0.4348 & 1219.6 & 891.5 & -8.8823 & 5.9748 & 2.7717 & 14.297 \\
\hline 0.6610 & 0.3390 & 1256.4 & 902.1 & -7.6509 & 4.3294 & 2.1623 & 11.048 \\
\hline 0.7521 & 0.2479 & 1296.1 & 913.2 & -5.8555 & 2.6513 & 1.4648 & 7.4111 \\
\hline 0.8389 & 0.1611 & 1333.9 & 923.8 & -4.0912 & 1.4773 & 0.8986 & 4.6051 \\
\hline 0.9213 & 0.0787 & 1371.1 & 934.4 & -2.0984 & 0.6249 & 0.4253 & 1.9982 \\
\hline 1.0000 & 0.0000 & 1408.0 & 944.6 & 0.0000 & 0.0000 & 0.0000 & 0.0000 \\
\hline
\end{tabular}

As shown in Table 1, the excess adiabatic compressibility $\beta^{\mathrm{E}}$ values are increasing with increase in mole fraction of $\mathrm{CY}$, reaches maximum at 0.43 mole fraction and then begins to decrease with further increase in mole fraction of $\mathrm{CY}$, more over the values are positive in both the systems studied. This positive trend indicates the presence of weak interaction between the molecules of components of the liquid mixtures. However, the magnitude of $\beta^{\mathrm{E}}$ values are less positive in the case of the Isobutyl acetate system than that of Isopropyl acetate system. This indicates that the less interaction in the former system. The possible reason may be because of two types of effects. One is the increase of electron density in the $\mathrm{O}-\mathrm{H}$ bond and the other is the steric effect. These two effects decrease the strength of the intermolecular hydrogen bond formation in the systems under study.

The intermolecular free length $\mathrm{Lf}$ has been calculated by using semi-empirical relation given by Jacobson [9]. The excess free length $\mathrm{L}_{\mathrm{f}}^{\mathrm{E}}$ follows the same trend as that of $\beta E$ in both the systems. These values are positive because of the fact that that the sound waves cover only short distance due to decrease in free length ascribing the dominant nature of dispersive forces. Fort et.al [10] indicated that the positive values of excess free length 
should attribute to dispersive forces and negative excess values should be due to charge transfer and hydrogen bond formation. In present study the positive contribution of $\mathrm{L}_{\mathrm{f}}^{\mathrm{E}}$ in both systems shows a weak interaction [11] between the molecules of alkyl acetates and cyclohexanone.

The excess molar volume $\mathrm{V}_{\mathrm{m}}{ }^{\mathrm{E}}$ values are positive over the entire composition range in both the binary mixtures. The value is maximum at 0.5 mole fraction for IPA and at 0.6 mole fraction for IBA. This suggests that the component molecules are not so close in the liquid mixtures as that of in the pure liquids forming the mixtures, indicating the weak interaction between component molecules. Another reason may be the presence non-specific physical interaction and unfavorable interaction between unlike molecules[12]. This leads to expansion of volume during mixing.

The whole discussion is well supported by the excess acoustic impedance $Z^{\mathrm{E}}$. The $\mathrm{Z}^{\mathrm{E}}$ values are negative over the entire mole fraction range and it is maximum at about 0.5 mole fraction of cyclohexanone. The negative trend of ZE clearly suggests that there is a weak molecular interactions existing between the unlike molecules. The reason may be that the rupture of the hydrogen bond chain of alkyl acetates dominates over that of the hydrogen bond formed between the unlike molecules.

\section{Conclusion}

From ultrasonic velocity, related acoustical parameters and their excess values, it is concluded that there exists a weak molecular association between the component molecules in the mixtures. Also it is found that bond breaking predominates over the other type of molecular interactions.

Further it is noticed that the weak interactions are more in the binary mixture of CY + IBA than in CY + IPA binary liquid mixture. This can be attributed to the increase of chain length in IBA.

\section{References}

1. Oswal.S.L., Oswal.P \& Pathak.R.P, J.Solution Chem, 1998, $27,507$.

2. Dewan.R.K., Mehata.S.K, Prahar.R \& Bala.K J.Che.Soc. Faraday Trans, 1991, 87, 1561.

3. U.Sridevi, K.Samatha J.Pure and Applied Ultrasonics 2004, 26, 1-11.

4. Manisha Gupta and Shukla J P, Indian J Pure Appl Phys., 1996, 34, 772.

5. Pankaj and Sharma C, Ultrasonics, 1991, 29, 344.

6. Velmurugan s, Nambinarayanan.T.K, Srinivasa Rao.A and Krishnan B, Indian J Phys., 1987, 61B, 105.

7. Tiwari K, Patra C, \& Chakravorthy V, Acoust Lett, 1995, 19, 53.

8. Kannappan AN \& Palaniappan L, Ind Journ Phys., 1999, 73B, 531.

9. Jacobson B, Acta Chem Scand.,1952, 6,1485.

10. Fort. R.J and Moore.W.R., Trans.faraday Soc.., 1968, 61, 2102.

11. Rajendran V and Marikani, Acoustics Lett., UK, 1994, 18, 90.

12. T.S.Jyotsna, Satyanarayana Ind Journ Chem. 2005, 44A ,1365-1371. 


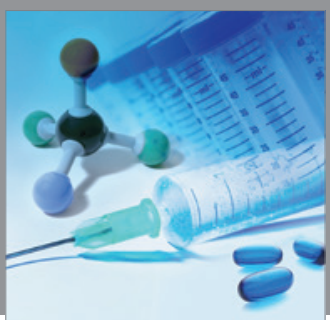

International Journal of

Medicinal Chemistry

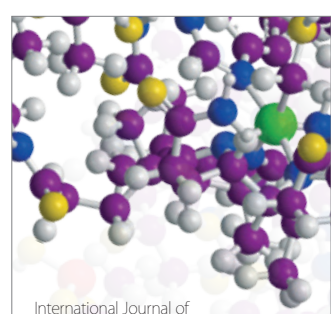

Carbohydrate Chemistry

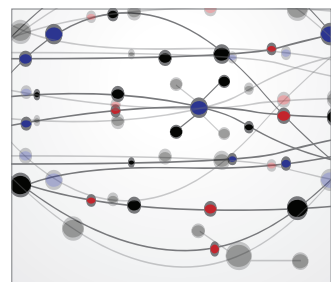

The Scientific World Journal
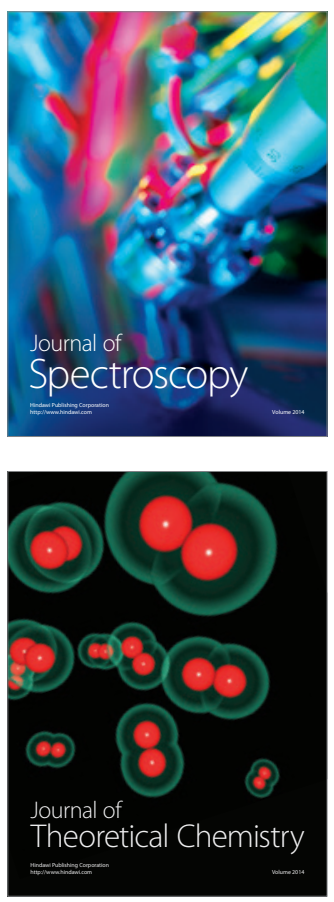
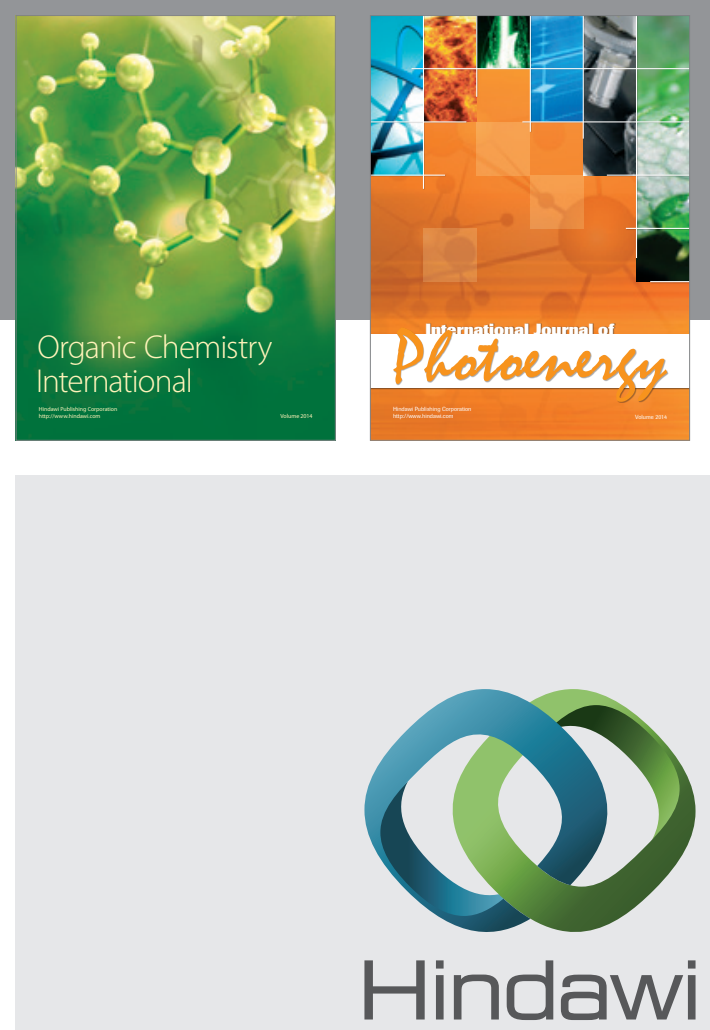

Submit your manuscripts at

http://www.hindawi.com
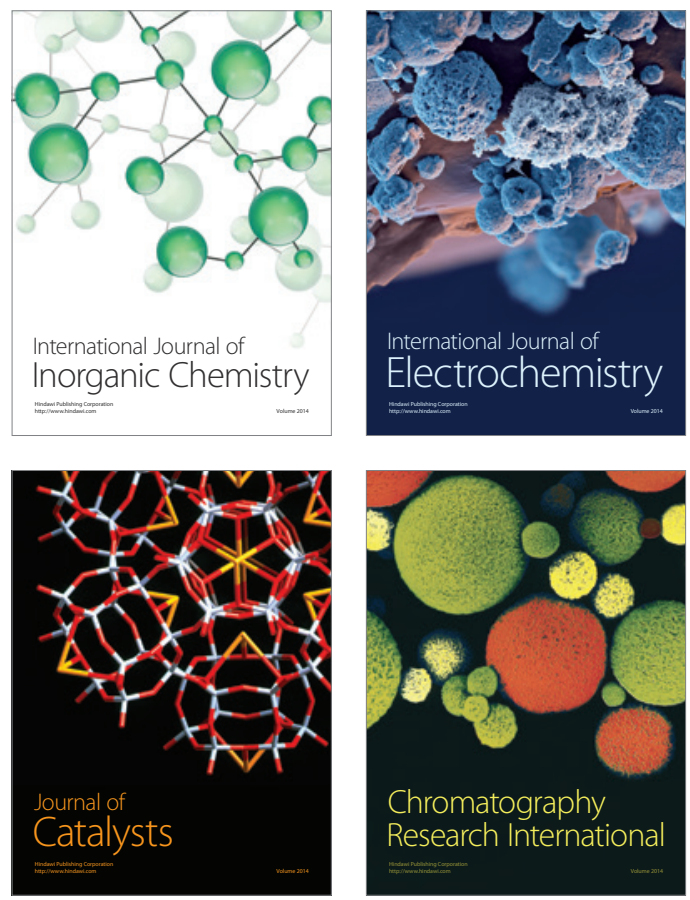
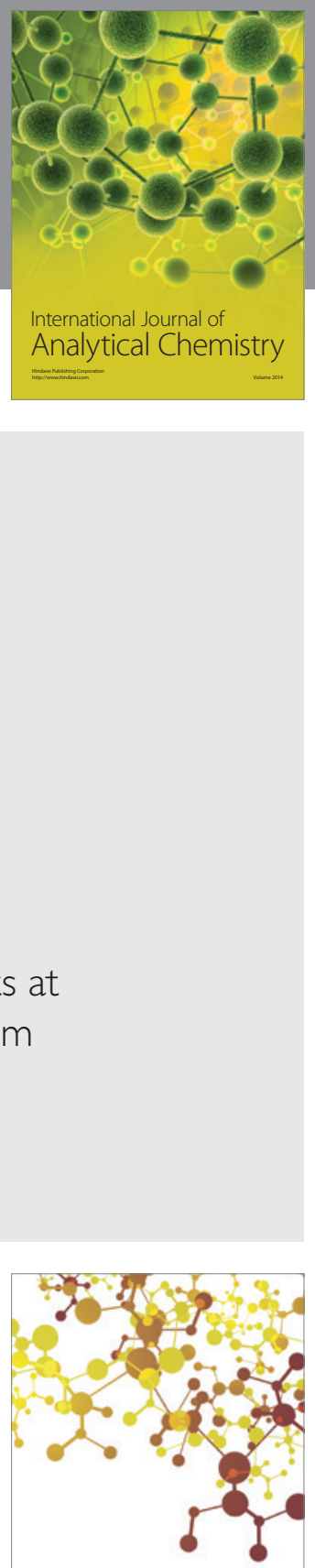

Journal of

Applied Chemistry
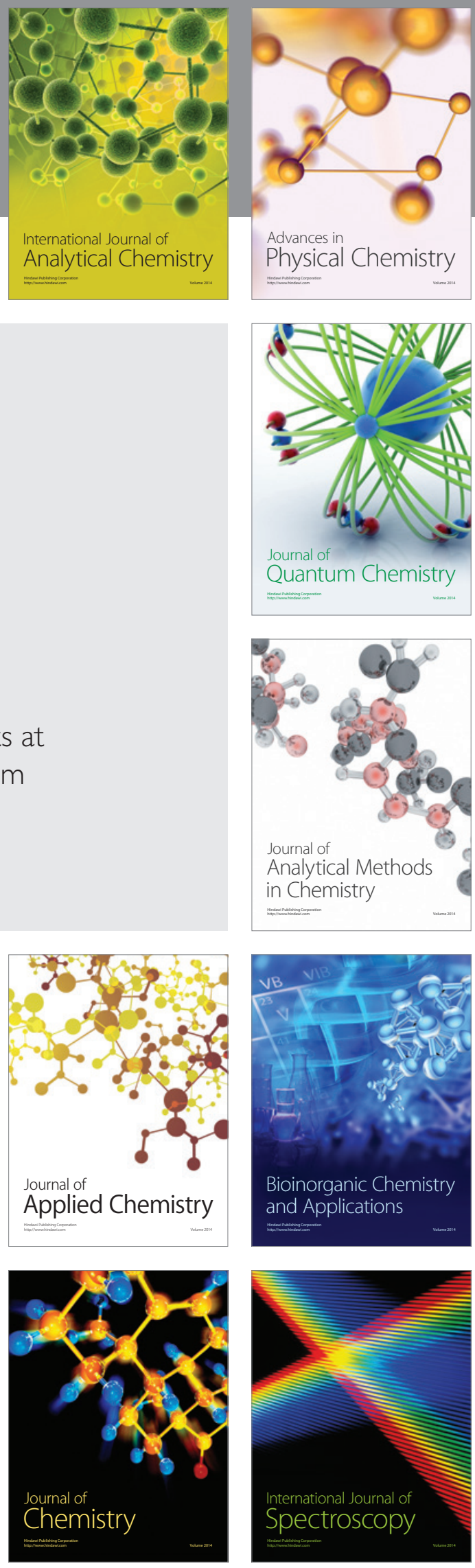